\title{
Energy Relaxation Rates in AllnN/AIN/GaN Heterostructures
}

\author{
E. TIRAS,${ }^{1,3}$ S. ARDALI,${ }^{1}$ E. ARSLAN,${ }^{2}$ and E. OZBAY ${ }^{2}$ \\ 1.-Department of Physics, Faculty of Science, Anadolu University, Yunus Emre Campus, 26470 \\ Eskisehir, Turkey. 2.-Nanotechnology Research Center, Department of Physics, and Department \\ of Electrical and Electronics Engineering, Bilkent University, 06800 Ankara, Turkey. 3.-e-mail: \\ etiras@anadolu.edu.tr
}

The two-dimensional (2D) electron energy relaxation in $\mathrm{Al}_{0.83} \mathrm{In}_{0.17} \mathrm{~N} / \mathrm{AlN} / \mathrm{GaN}$ heterostructures has been investigated experimentally. Shubnikov-de Haas $(\mathrm{SdH})$ effect measurements were employed in the investigations. The electron temperature $\left(T_{\mathrm{e}}\right)$ of hot electrons was obtained from the lattice temperature $\left(T_{\mathrm{L}}\right)$ and the applied electric field dependencies of the amplitude of $\mathrm{SdH}$ oscillations. The experimental results for the electron temperature dependence of power loss are also compared with current theoretical models for power loss in 2D semiconductors. The power loss from the electrons was found to be proportional to $\left(T_{\mathrm{e}}^{3}-T_{\mathrm{L}}^{3}\right)$ for electron temperatures in the range $1.8 \mathrm{~K}<T_{\mathrm{e}}<14 \mathrm{~K}$, indicating that the energy relaxation of electrons is due to acoustic phonon emission via unscreened piezoelectric interaction. The effective mass and quantum lifetime of the $2 \mathrm{D}$ electrons have been determined from the temperature and magnetic field dependencies of the amplitude of $\mathrm{SdH}$ oscillations, respectively. The values obtained for quantum lifetime suggest that remote ionized impurity scattering is the dominant scattering mechanism in $\mathrm{Al}_{0.83} \mathrm{In}_{0.17} \mathrm{~N} / \mathrm{AlN} / \mathrm{GaN}$ heterostructures.

Key words: GaN heterostructure, electron energy relaxation, power loss, phonon emission, Shubnikov-de Haas, Hall mobility

\section{INTRODUCTION}

Group III-nitride materials are very suitable for applications in high-power, high-frequency, and high-temperature electronics. ${ }^{1}$ Knowledge on fundamental electron transport properties, such as the effective mass of two-dimensional (2D) electrons and relaxation times, is important for exploration and optimization of this material system for device applications. Device performance under high electric field is also important for these systems. At high electric field, the electrons equilibrate at much higher temperature than the lattice temperature. Therefore, determination of the temperature of those hot electrons is of technological and fundamental importance.

The energy relaxation of hot carriers in semiconductors via electron-phonon interaction has been investigated extensively, both experimentally and

(Received February 6, 2012; accepted May 25, 2012;

published online June 27, 2012) theoretically, in bulk and two-dimensional 2D structures (for review see Refs. 2-4). The determination of the temperature of electrons, under electric field heating conditions in the steady state, provides useful information about the electronphonon interactions involved in the energy relaxation process. Since, at temperatures below approximately $30 \mathrm{~K}$ to $40 \mathrm{~K}$, the population of optical phonons is negligibly small, acoustic phonon scattering provides the only inelastic scattering mechanism. ${ }^{4-7}$

There are four experimental techniques that have been widely employed, successfully, in investigations of electron relaxation. First, in heavily modulationdoped structures where a highly degenerate electron gas exists, the variation of the amplitude of quantum oscillations, such as in the Shubnikov-de Haas (SdH) effect, with the applied field and lattice temperature can be used in the determination of the electron temperature-power loss characteristics. ${ }^{3,8,9}$ Second, in a material where the momentum relaxation is dominated by ionized impurity, remote impurity, interface 
roughness, or optical phonon scattering, ${ }^{8-11}$ electron temperatures can be determined as a function of the applied electric field by a simple comparison of the electric field-dependent and lattice temperaturedependent mobility curves. ${ }^{8-10,12,13}$ Third, using the noise technique, the electron temperature can be estimated by measuring the electromagnetic radiation results of fluctuations in the electron velocities under high electric field. ${ }^{14,15}$ Fourth, with the pump-probe Raman spectroscopy technique, the energy relaxation time can be directly determined from the decay of the anti-Stokes line intensity. ${ }^{16}$

Electron energy relaxation rates in GaN-based samples have been investigated using the different techniques described above. ${ }^{12-20}$ In GaN-based heterostructures, a two-dimensional electron gas (2DEG) is formed at the GaN side of the interface between the barrier and GaN layers. Insertion of a thin AlN spacer layer between the barrier and GaN layers helps to increase electron mobility. ${ }^{21-23}$

In-depth understanding of the fundamental optical and electronic properties is yet to be established for the design and development of functional devices. Determination of the temperature of electrons, under electric field heating conditions in the steady state, provides useful information about the electron-phonon interactions involved in the energy relaxation process. ${ }^{2,5}$ Furthermore, electron-phonon scattering processes determine the high-field transport phenomena in semiconductors and thus form the basis for many ultrafast electronic and optoelectronic devices. The field of hot carriers in semiconductors thus provides a link between fundamental semiconductor physics and high-speed devices. ${ }^{24}$ Despite the fact that the energy relaxation time is a scientifically, technologically, and fundamentally important parameter for designing optoelectronic devices, it is not yet well known. In this work, the temperature of hot electrons $\left(T_{\mathrm{e}}\right)$ of the sample and the corresponding power loss $(P)$ have been determined as a function of the applied electric field using the $\mathrm{SdH}$ effect method in $\mathrm{Al}_{0.83} \mathrm{In}_{0.17}$ N/AlN/GaN heterostructures. The experimental results determined from $\mathrm{SdH}$ measurements are also compared with a two-dimensional model in the acoustic phonon regime. The results are discussed in the framework of current theoretical models concerning carrier energy loss rates in dilute semiconductors.

\section{THEORETICAL BACKGROUND}

Magnetotransport measurements have been extensively used in investigations of the electronic transport properties of $2 \mathrm{D}$ structures at low temperature. $\mathrm{SdH}$ oscillations in the magnetoresistance provide an accurate and sensitive technique that has been employed successfully in investigations of electron energy relaxation in the acoustic phonon regime. ${ }^{3,25,26}$ In heavily modulation-doped structures, where a highly degenerate electron gas exists,
Table I. Electronic transport properties of the AlIn N/AIN/GaN heterojunction determined at $1.8 \mathrm{~K}$

\begin{tabular}{|c|c|}
\hline Parameter & Value \\
\hline $2 \mathrm{D}$ carrier density, $N_{2 \mathrm{D}}\left(10^{16} \mathrm{~m}^{-2}\right)$ & 7.25 \\
\hline Sheet carrier density, $N_{\mathrm{H}}\left(10^{16} \mathrm{~m}^{-2}\right)$ & 11.88 \\
\hline Effective mass, $m^{*}\left(m_{0}\right)$ & 0.188 \\
\hline Fermi energy, $E_{\mathrm{F}}-E_{1}(\mathrm{meV})$ & 92.26 \\
\hline Hall mobility, $\mu_{\mathrm{H}}\left(\mathrm{cm}^{2} \mathrm{~V}^{-1} \mathrm{~s}^{-1}\right)$ & 6858 \\
\hline Transport mobility, $\mu_{\mathrm{t}}\left(\mathrm{cm}^{2} \mathrm{~V}^{-1} \mathrm{~s}^{-1}\right)$ & 7820 \\
\hline Parallel channel mobility, $\mu_{\mathrm{B}}\left(\mathrm{cm}^{2} \mathrm{~V}^{-1} \mathrm{~s}^{-1}\right)$ & 3800 \\
\hline Transport lifetime, $\tau_{\operatorname{tr}}\left(10^{-12} \mathrm{~s}\right)$ & 0.836 \\
\hline Quantum lifetime, $\tau_{\mathrm{q}}\left(10^{-12} \mathrm{~s}\right)$ & 0.264 \\
\hline Lifetime ratio, $\tau_{\mathrm{tr}} / \tau_{\mathrm{q}}$ & 3.2 \\
\hline & 3.55 \\
\hline$A\left(\mathrm{eV} \mathrm{s}^{-1} \mathrm{~K}^{-\gamma}\right)$ & 2.9 \\
\hline
\end{tabular}

variations of the amplitude of the $\mathrm{SdH}$ oscillations with applied electric field and lattice temperature can be used in the determination of the power loss-electron temperature characteristics. The sample used in the present study is highly degenerate, so that the reduced Fermi energy $\eta=\left(E_{\mathrm{F}}-E_{1}\right) / k_{\mathrm{B}} T \gg 1$ (Table I), even at electron temperatures of approximately $30 \mathrm{~K}$, which is well above the range of temperatures considered here. Therefore, we employed the $\mathrm{SdH}$ oscillations technique in our investigations. The method is based on the assumption that ionized impurity scattering, alloy scattering, and interface roughness scattering, which determine the low-temperature transport mobility of electrons, are elastic in nature. Consequently, the energy that is gained by electrons in an applied electric field is dissipated via emission of acoustic phonons. ${ }^{2,5-7,23,27-32}$

The $\mathrm{SdH}$ oscillations in the magnetoresistance of a 2D electron gas of single-subband occupancy are well described by the analytical function ${ }^{33,34}$

$$
\frac{\Delta \rho_{x x}}{\rho_{0}} \propto D(\chi) \exp \left(\frac{-\pi}{\omega_{\mathrm{c}} \tau_{\mathrm{q}}}\right) \cos \left[\frac{2 \pi\left(E_{\mathrm{F}}-E_{1}\right)}{\hbar \omega_{\mathrm{c}}}-\pi\right],
$$

where $\Delta \rho_{x x}, \rho_{0}, E_{\mathrm{F}}, E_{1}, \omega_{\mathrm{c}}\left(=e B / m^{*}\right), \tau_{\mathrm{q}}$, and $\hbar$ are the oscillatory magnetoresistivity, zero-magnetic-field resistivity, Fermi energy, first subband energy, cyclotron frequency, quantum lifetime, and Planck's constant, respectively. The exponential term, $\exp \left(-\pi / \omega_{\mathrm{c}} \tau_{\mathrm{q}}\right)$, describes the damping due to the collision broadening of the Landau levels. The temperature dependence of the envelope function of the $\mathrm{SdH}$ oscillations is totally contained in the term

$$
D(\chi)=\frac{\chi}{\sinh \chi}
$$

with

$$
\chi=\frac{2 \pi^{2} k_{\mathrm{B}} T}{\hbar \omega_{\mathrm{c}}},
$$


where $k_{\mathrm{B}}$ is the Boltzmann constant. The $2 \mathrm{D}$ carrier density $\left(N_{2 \mathrm{D}}\right)$ can be calculated ${ }^{25}$ using the arguments of Eq. (1)

$$
\triangle\left(\frac{1}{B}\right)=\frac{e}{\pi \hbar N_{2 \mathrm{D}}}=\frac{e \hbar}{m^{*}\left(E_{F}-E_{1}\right)} .
$$

The thermal damping of the amplitude of the $\mathrm{SdH}$ oscillations is, therefore, determined by the temperature, magnetic field, and effective mass via

$$
\frac{A\left(T, B_{n}\right)}{A\left(T_{0}, B_{n}\right)}=\frac{T \sinh \left(2 \pi^{2} k_{\mathrm{B}} T_{0} m^{*} / \hbar e B_{n}\right)}{T_{0} \sinh \left(2 \pi^{2} k_{\mathrm{B}} T m^{*} / \hbar e B_{n}\right)},
$$

where $A\left(T, B_{n}\right)$ and $A\left(T_{0}, B_{n}\right)$ are the amplitudes of the oscillation peaks observed at magnetic field $B_{n}$ and temperatures $T$ and $T_{0}$. In the derivation of Eq. (4) from Eq. (1) it has been assumed that the quantum lifetime $\left(\tau_{q}\right)$ is independent of both the temperature and the magnetic field. The quantum lifetime can be determined from the magnetic field dependence of the amplitude of the $\mathrm{SdH}$ oscillations (i.e., Dingle plots) at constant temperature provided that the electron effective mass is known ${ }^{25,26,35}$

$$
\ln \left[\frac{A\left(T, B_{n}\right) \cdot B_{n}^{-1 / 2} \cdot \sinh (\chi)}{\chi}\right]=C-\frac{\pi m^{*}}{e \tau_{q}} \frac{1}{B_{n}},
$$

where $C$ is a constant.

At low temperatures, the contribution to the energy relaxation rates by elastic scattering mechanisms, such as ionized impurity scattering, alloy disorder scattering, and interface roughness scattering, can be neglected. ${ }^{2}$ Therefore, inelastic scattering mechanisms should be considered in order to explain the rise of temperature of the $2 \mathrm{D}$ electron gas where the applied electric field causes the heating of electrons. Typically, at temperatures below $30 \mathrm{~K}$, longitudinal optical phonon scattering becomes negligible and the main source of energy relaxation is acoustic phonon scattering. Scattering from acoustic phonons includes two independent processes: deformation potential (nonpolar acoustic) scattering and piezoelectric (polar acoustic) scattering. At low temperatures, the carrier distribution is often degenerate, and Pauli exclusion is important in limiting the scattering that is allowed. ${ }^{2,5-7,28-30} \mathrm{In}$ the $2 \mathrm{D}$ calculations, the scattering by the absorption of acoustic phonons was neglected and only spontaneous emission was considered to be important, the infinite-well approximation was used in the extreme quantum limit, and the phonons were assumed to be bulk phonons. ${ }^{2,3}$

The power loss from a degenerate electron gas due to scattering by acoustic phonons has been calculated in two temperature regimes ${ }^{2,6,7,29}$ : (i) the low-temperature regime, where the electron temperature $T_{\mathrm{e}} \ll T_{\mathrm{e}}^{\mathrm{c}}$, and (ii) the high-temperature regime, where $T_{\mathrm{e}} \gg T_{\mathrm{e}}^{\mathrm{c}}$, hence the critical electron temperature is given ${ }^{29}$ by

$$
T_{\mathrm{e}}^{\mathrm{c}}=\frac{\left[8 m^{*} V_{\mathrm{S}}^{2}\left(E_{\mathrm{F}}-E_{1}\right)\right]^{1 / 2}}{k_{\mathrm{B}}},
$$

where $V_{\mathrm{S}}$ is the sound velocity. The regime between these two temperature limits is called the intermediate regime. ${ }^{2,3}$

In the low-temperature (Bloch-Grüneisen) regime $\left.\left(\hbar \omega_{\mathrm{q}} / k_{\mathrm{B}} T_{\mathrm{e}} \gg 1\right)\right)$ the phonon distribution is given $^{3}$ by

$$
n\left(\omega_{\mathrm{q}}\right)=\frac{1}{\exp \left(\hbar \omega_{\mathrm{q}} / k_{\mathrm{B}} T_{\mathrm{L}}\right)-1} \cong \exp \left(-\frac{\hbar \omega_{\mathrm{q}}}{k_{\mathrm{B}} T_{\mathrm{L}}}\right),
$$

where $\hbar \omega_{\mathrm{q}}$ is the acoustic phonon energy at wavevector q. At low temperatures, the Fermi gas has a sharp boundary curve, and consequently momentum changes that involve the emission of an acoustic phonon of energy much greater than $k_{\mathrm{B}} T_{\mathrm{e}}$ are hindered greatly by Pauli exclusion, and hence only small-angle scattering is allowed at very low temperatures. ${ }^{28,36}$ Then, in the case under discussion, low-angle scattering should occur in the first subband, which is characterized by the dependencies $P_{\mathrm{np}} \propto\left(T_{\mathrm{e}}^{5}-T_{\mathrm{L}}^{5}\right)$ for deformation potential scattering and $P_{\mathrm{np}} \propto\left(T_{\mathrm{e}}^{3}-T_{\mathrm{L}}^{3}\right)$ for piezoelectric scattering. ${ }^{28,29}$ Therefore, the total energy loss rate of a $2 \mathrm{D}$ electron gas, $P=P_{\mathrm{np}}+P_{\mathrm{p}}$, in the low-temperature regime, can be represented ${ }^{2,3}$ by

$$
P=C_{\mathrm{np}}\left[\left(k_{\mathrm{B}} T_{\mathrm{e}}\right)^{5}-\left(k_{\mathrm{B}} T_{\mathrm{L}}\right)^{5}\right]+C_{\mathrm{p}}\left[\left(k_{\mathrm{B}} T_{\mathrm{e}}\right)^{3}-\left(k_{\mathrm{B}} T_{\mathrm{L}}\right)^{3}\right],
$$

where

$$
C_{\mathrm{np}}=\frac{6 \Xi^{2} m^{* 2} L_{z}}{\pi^{3} \rho \hbar^{7} V_{\mathrm{S}}^{4} N_{2 \mathrm{D}}}
$$

and

$$
C_{\mathrm{p}}=\frac{e^{2} K_{\mathrm{av}}^{2} m^{* 2}}{2 \pi^{2} \epsilon_{\mathrm{s}} \hbar^{5} k_{\mathrm{F}} N_{2 \mathrm{D}}} ;
$$

are the magnitudes of the deformation potential and piezoelectric interactions, respectively. Here, $\Xi$ is the acoustic deformation potential, $\rho$ is the mass density, $\epsilon_{\mathrm{S}}$ is the static permittivity, and $k_{\mathrm{F}}=$ $\left[2 \pi N_{2 \mathrm{D}}\right]^{1 / 2}$ is the Fermi wavevector of $2 \mathrm{D}$ electrons in which $N_{2 \mathrm{D}}$ is the $2 \mathrm{D}$ carrier density. The average electromechanical coupling constant $K_{\mathrm{av}}^{2}$ for cubic crystal is given ${ }^{3}$ by

$$
K_{\mathrm{av}}^{2}=\frac{e_{14}^{2}}{\epsilon_{\mathrm{s}}}\left[\frac{12}{35 C_{\mathrm{L}}}+\frac{16}{35 C_{\mathrm{T}}}\right]
$$

Here, $e_{14}$ is the piezoelectric stress constant, and $C_{\mathrm{L}}$ and $C_{\mathrm{T}}$ are the average longitudinal and transverse elastic constants, given ${ }^{37}$ in terms of the components of the elastic stiffness constants $C_{i j}$ by

$$
C_{\mathrm{L}}=C_{11}+\frac{2}{5}\left(C_{12}+C_{44}-C_{11}\right)
$$


and

$$
C_{\mathrm{T}}=C_{44}-\frac{1}{5}\left(C_{12}+2 C_{44}-C_{11}\right) .
$$

The screening of the electron-phonon interaction in the 2D case, which is not included in the above calculations, is predicted to increase the exponent of the $k_{\mathrm{B}} T_{\mathrm{e}}$ and $k_{\mathrm{B}} T_{\mathrm{L}}$ terms in Eq. (8) by two. ${ }^{2,5}$

We assumed that the effective well width $\left(L_{z}\right)$ of the potential well at the $\mathrm{Al}_{0.83} \mathrm{In}_{0.17} \mathrm{~N} / \mathrm{AlN}$ interface approximately equals the average distance of the electrons from the interface derived for only the lowest subband occupied structures using the Fang-Howard variational wave function ${ }^{34}$

$$
L_{z} \approx z_{0}=\left[\frac{9 \epsilon_{\mathrm{s}} \hbar^{2}}{4 m^{*} e^{2}\left(N_{\mathrm{depl}}+11 N_{2 \mathrm{D}} / 32\right)}\right]^{1 / 3},
$$

where $N_{\text {depl }}=\left(2 \epsilon_{\mathrm{s}} V_{\mathrm{b}}\left(N_{\mathrm{D}}-N_{\mathrm{A}}\right) / e\right)^{1 / 2}$ is the depletion layer charges per unit area, $V_{\mathrm{b}}$ is the conductionband energy offset, $N_{\mathrm{D}}$ is the donor concentration, and $N_{\mathrm{A}}$ is the acceptor concentration.

The variation of the power loss per electron with electron temperature has been often approximated by the relationship

$$
P=A\left(T_{\mathrm{e}}^{\gamma}-T_{\mathrm{L} 0}^{\gamma}\right)
$$

where $T_{\mathrm{L} 0}$ is the lowest lattice temperature and $A$ is a proportionality constant that depends on the elastic moduli of the matrix, the coupling constants, and the 2D carrier density. Theoretical calculations of the acoustic phonon-assisted energy loss rates of hot electrons in a $2 \mathrm{D}$ electron gas of single subband occupancy predict $\gamma=1$ at high temperatures (when Maxwell-Boltzmann statistics is applicable and equipartition is assumed) and $\gamma=3$ (unscreened piezoelectric scattering), $\gamma=5$ (unscreened deformation potential and heavily screened piezoelectric scatterings), and $\gamma=7$ (heavily screened deformation potential scattering) at low temperatures (see, for instance, Refs. 2,28-30,38).

\section{EXPERIMENTAL PROCEDURES}

$\mathrm{Al}_{1-x} \mathrm{In}_{x} \mathrm{~N} / \mathrm{AlN} / \mathrm{GaN} \quad(x=0.17)$ heterostructures were grown on double-polished 2-inch-diameter sapphire $\left(\mathrm{Al}_{2} \mathrm{O}_{3}\right)$ substrates in a low-pressure metalorganic chemical vapor deposition (MOCVD) reactor (Aixtron 200/4 HT-S) by using trimethylgallium (TMGa), trimethylaluminum (TMAl), and ammonia as $\mathrm{Ga}, \mathrm{Al}$, and $\mathrm{N}$ precursors, respectively. Prior to the epitaxial growth, $\mathrm{Al}_{2} \mathrm{O}_{3}$ substrate was annealed at $1100^{\circ} \mathrm{C}$ for $10 \mathrm{~min}$ in order to remove surface contamination. The buffer structures consisted of a 15-nm-thick, low-temperature $\left(770^{\circ} \mathrm{C}\right)$ AlN nucleation layer, and high-temperature $\left(1120^{\circ} \mathrm{C}\right) 270-\mathrm{nm}$ AlN templates. A $1.16-\mu \mathrm{m}$, nominally undoped GaN layer was grown on an AlN template layer at $1060^{\circ} \mathrm{C}$, followed by a $1.5-\mathrm{nm}$ thick high-temperature $\left(1075^{\circ} \mathrm{C}\right)$ AlN spike layer.
The AlN barrier layer was used to reduce the alloy disorder scattering by minimizing the wave function penetration from the two-dimensional electron gas (2DEG) channel into the AlInN layer. After deposition of these layers, we used 1-nm $\operatorname{AlN}\left(1075^{\circ} \mathrm{C}\right)$ and $3-\mathrm{nm} \mathrm{GaN}\left(1075^{\circ} \mathrm{C}\right)$ between the $\mathrm{Al}_{0.83} \mathrm{In}_{0.17} \mathrm{~N}$ barrier layer and the AlN spike layer. The thickness of the $\mathrm{Al}_{0.83} \operatorname{In}_{0.17} \mathrm{~N}$ barrier layer was $13 \mathrm{~nm}$, and it was grown at $830^{\circ} \mathrm{C}$. Finally, a 2 -nm-thick GaN cap layer growth was carried out at temperature of $830^{\circ} \mathrm{C}$. After the growth, these parameters were measured for each wafer, using standard characterization techniques, such as transmission electron microscopy (TEM), capacitance-voltage profiling, and high-resolution x-ray analysis.

Measurements of longitudinal resistance along the direction of applied current $\left(R_{x x}\right)$ were carried out as functions of: (i) the applied electric field $F$ at fixed lattice temperature $T_{\mathrm{L} 0}$, and (ii) lattice temperature $T_{\mathrm{L}}$ at a fixed electric field $F_{0}$ that was low enough to ensure ohmic conditions and hence to avoid carrier heating. In the experiments, a conventional direct-current (DC) technique in combination with a constant-current source (Keithley 2400) and a nanovoltmeter (Keithley 2182A) in a cryogen-free superconducting magnet system (model J2414; Cryogenics Ltd.) were used. The current $(I)$ flow was in the plane of the electron gas. Steady magnetic fields up to $11 \mathrm{~T}$ were applied perpendicular to the plane of the samples and, therefore, to the plane of the $2 \mathrm{D}$ electron gas. All measurements were taken in the dark. To check the $2 \mathrm{D}$ nature of the electron gas giving rise to the quantum oscillations in magnetoresistance, measurements were also performed as a function of the angle $\theta$ between the normal to the plane of the $2 \mathrm{D}$ electron gas and the applied magnetic field. It was found that the peak position shifted with a factor of $\cos \theta$ and the oscillations disappeared at $\theta=90^{\circ}$. This observation is a characteristic of a $2 \mathrm{D}$ electron gas. $^{25}$

For the classical low-magnetic-field temperaturedependent Hall-effect measurements, $R_{x x}$ and the Hall resistance $\left(R_{x y}\right)$ were measured as a function of temperature from $1.8 \mathrm{~K}$ to $275 \mathrm{~K}$. A static magnetic field $(B=1 \mathrm{~T})$ was applied to the sample perpendicular to the current plane. The Hall mobility $\left(\mu_{\mathrm{H}}\right)$ and the sheet carrier density $\left(N_{\mathrm{H}}\right)$ were obtained using the following equations:

$$
\begin{gathered}
R_{x y}=\frac{B}{N_{\mathrm{H}} e}, \\
\mu_{\mathrm{H}}=\frac{L}{N_{\mathrm{H}} e R_{x x} b},
\end{gathered}
$$

where $b(=0.6 \mathrm{~mm})$ and $L(=1 \mathrm{~mm})$ are the width and length of the Hall bar. The applied electric field was also obtained using the longitudinal resistance measured at $B=0 \mathrm{~T}\left(R_{x x}(B=0)=118 \Omega\right)$ in the following equation: 


$$
F=\frac{R_{x x}(B=0) I}{L} .
$$

In the applied electric field-dependent magnetoresistance measurements, current was applied along the length of the sample in the range of $I=100 \mu \mathrm{A}$ to $2000 \mu \mathrm{A}$.

The Raman spectra were obtained at room temperature using a Bruker Optics FT-Raman Scope III system. As an excitation source, a wavelength of $785 \mathrm{~nm}(1.58 \mathrm{eV})$ was applied in the sample growth direction ( $c$-axis).

\section{RESULTS AND DISCUSSION}

The temperature dependence of the sheet carrier density and Hall mobility in the $\mathrm{Al}_{0.83} \mathrm{In}_{0.17} \mathrm{~N} / \mathrm{AlN} /$ $\mathrm{GaN}$ heterostructure is plotted in Fig. 1. At low temperatures, the sheet carrier density remains practically constant up to temperature of $30 \mathrm{~K}$. At higher temperatures, the sheet carrier density increases monotonically with increasing temperature, possibly due to thermally generated carriers located outside the channel. We note that a decrease in the sheet carrier density has been observed in the temperature range from $30 \mathrm{~K}$ to $90 \mathrm{~K}$ (Fig. 1). A similar behavior of carrier density with temperature, although less pronounced, was reported previously for modulation-doped $\mathrm{GaAs} / \mathrm{Ga}_{1-x} \mathrm{Al}_{x} \mathrm{As}$ heterojunctions. ${ }^{39-41}$

The Hall mobility of electrons in the $\mathrm{Al}_{0.83} \mathrm{In}_{0.17} \mathrm{~N} /$ AlN/GaN heterostructure increases monotonically with decreasing temperature from room temperature, begins to level off at about $100 \mathrm{~K}$, and saturates at about $30 \mathrm{~K}$ (Fig. 1). This behavior reflects the $2 \mathrm{D}$ character of the electrons in the channel. ${ }^{25}$ In the temperature range below $30 \mathrm{~K}$, the mobilities measured for the sample are essentially independent of temperature. A similar behavior for the variation of Hall mobility with temperature was reported $^{14}$ for a lattice-matched AlInN/AlN/GaN sample with a 1-nm spacer layer that helps to

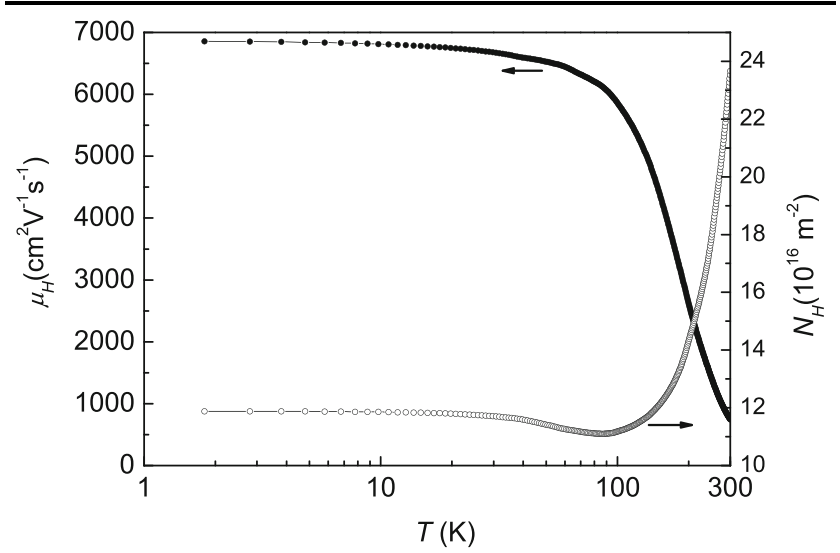

Fig. 1. Temperature dependence of the sheet carrier density $\left(N_{H}\right)$ and Hall mobility $\left(\mu_{\mathrm{H}}\right)$ of electrons in the $\mathrm{Al}_{0.83} \mathrm{n}_{0.17} \mathrm{~N} / \mathrm{AIN} / \mathrm{GaN}$ heterostructure. reduce remote alloy scattering and achieve high electron mobility (see, for instance, Refs. 21-23,42).

Figure 2 shows typical examples of the magnetoresistance $R_{x x}(B)$ measured at different temperatures and applied electric fields for $\mathrm{Al}_{0.83} \mathrm{In}_{0.17} \mathrm{~N} / \mathrm{AlN} /$ GaN heterostructures. SdH oscillations are clearly visible over the magnetic field range between $B=7 \mathrm{~T}$ and $11 \mathrm{~T}$. No higher harmonics are apparent in the oscillations. It is also evident that the oscillatory effect is superimposed on a monotonically increasing component, which occurs as a result of positive magnetoresistance in the barriers. ${ }^{3}$ This may affect the accuracy of the determination of the oscillation amplitude, particularly at elevated temperatures. Stradling and Wood ${ }^{43}$ adopted the following method to detect the oscillatory component of the magnetoresistance by removing the monotonic component $\left(R_{\mathrm{b}}\right)$. Therefore, we used the negative second derivative of the raw magnetoresistance data with respect to the magnetic field, i.e. $\left.\left(-\partial^{2} R_{x x} / \partial B^{2}\right)\right)^{3,25,26,43,44}$ The $\mathrm{SdH}$ oscillations have also been obtained by subtracting the background magnetoresistance (in the form of a polynomial of second degree) from the raw experimental data $\left(\Delta R=R_{x x}-R_{\mathrm{b}}\right){ }^{45}$ The values obtained for effective mass and quantum lifetime from the temperature and magnetic field dependence of the normalized amplitude of the oscillations in
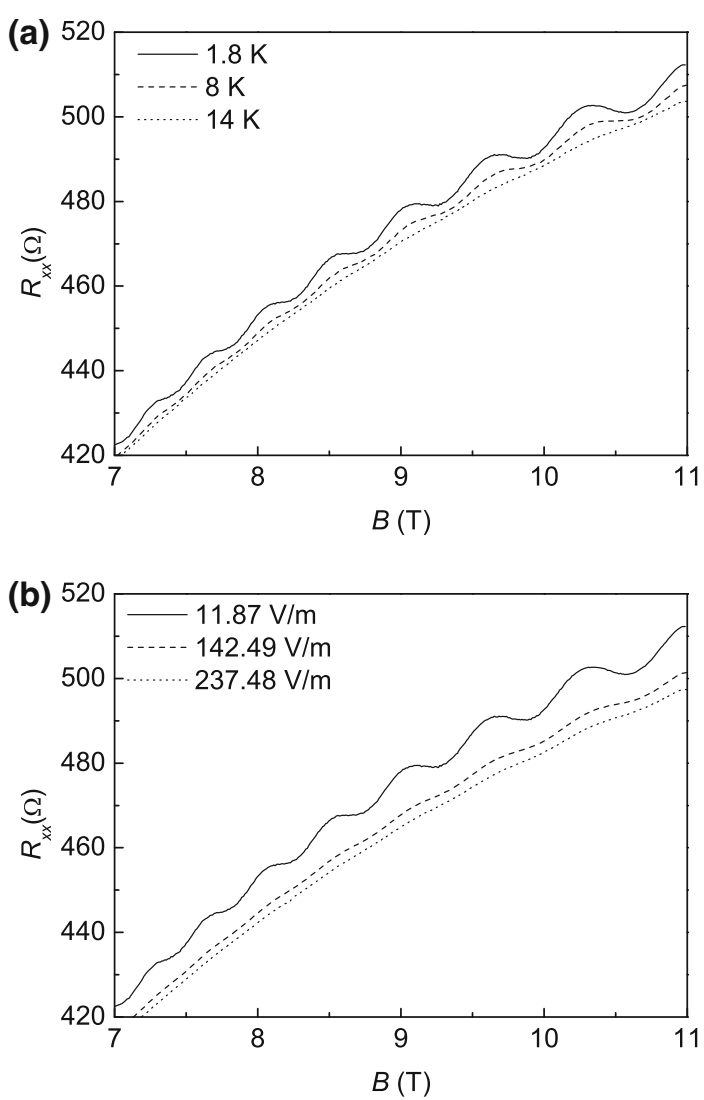

Fig. 2. Experimental results showing the effects of (a) temperature and (b) applied electric field on the magnetoresistance $R_{x x}(B)$ measured for an $\mathrm{Al}_{0.83} \mathrm{In}_{0.17} \mathrm{~N} / \mathrm{AIN} / \mathrm{GaN}$ heterostructure sample. 

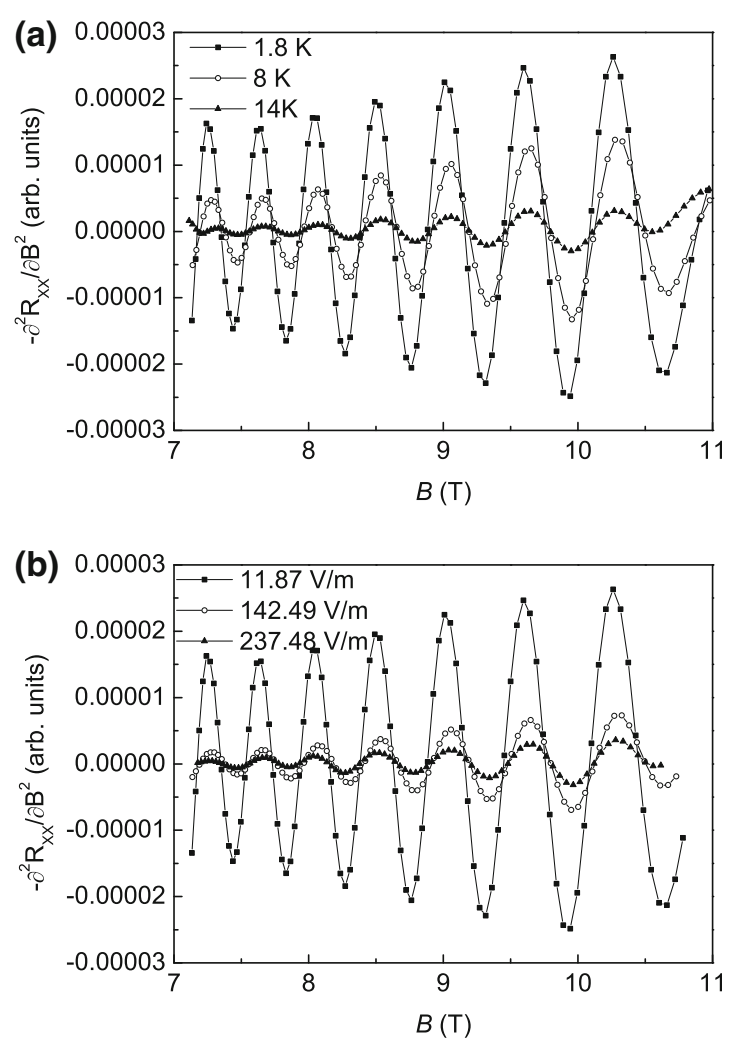

Fig. 3. Effects of temperature (a) and applied electric field (b) on the $\mathrm{SdH}$ oscillations arising from the electrons in the subband, as extracted from the $R_{x x}(B)$ data for an $\mathrm{Al}_{0.83} \mathrm{In}_{0.17} \mathrm{~N} / \mathrm{AIN} / \mathrm{GaN}$ heterostructure sample (shown in Fig. 1). The solid curves through the experimental data points are intended as a guide for the eye. The double differentiation removes the background magnetoresistance without affecting the position or amplitude of the oscillatory component.

$-\partial^{2} R_{x x} / \partial B^{2}$ agree to within $1 \%$ with those found from that of the oscillations in $\Delta R_{x x}=R_{x x}-R_{\mathrm{b}}$. The oscillations in the second derivative of magnetoresistance have well-defined envelopes and are symmetrical about the horizontal line as shown in Fig. 3. The double-differentiation technique does not change the peak position or the period of the oscillations. $^{25}$

The period of the SdH oscillations has been obtained from plots of the reciprocal magnetic field $\left(1 / B_{n}\right)$, at which the $n$th peak occurs, against the peak number $n$. If electrons in only one subband participate in the $\mathrm{SdH}$ oscillations, the graph of $1 / B_{n}$ versus $n$ gives a straight line (Fig. 4 ), the slope of which yields the oscillation period, $\Delta(1 / B)$. The Fourier analysis of the $\mathrm{SdH}$ oscillations (see the insert in Fig. 4) confirms that only the first subband is populated and that the contribution of higher harmonics is insignificant. The 2D carrier density $\left(N_{2 \mathrm{D}}\right)$ can be calculated using ${ }^{25}$ Eq. (3). The oscillation period (and hence the carrier density) that is determined from the SDH oscillation measurements is found to be essentially independent of temperature in the range from $1.8 \mathrm{~K}$ to $14 \mathrm{~K}$. The Fermi energies with respect to the subband energy

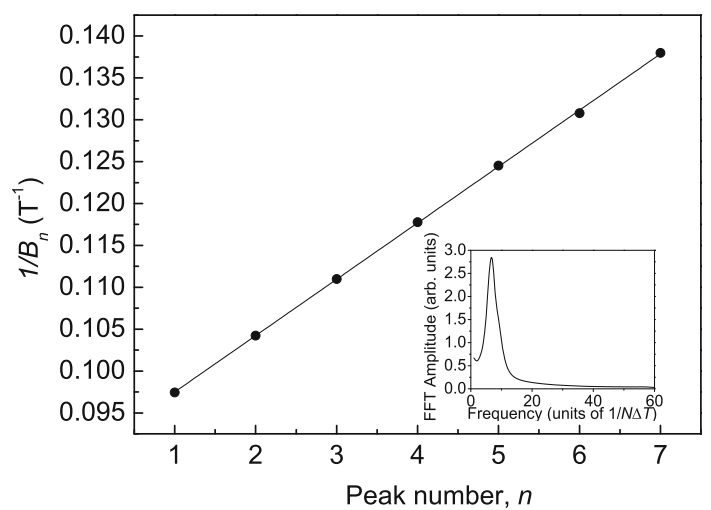

Fig. 4. The reciprocal magnetic field $\left(1 / B_{n}\right)$ plotted as a function of the oscillation peak number $(n)$ of $\mathrm{Al}_{0.83} \mid \mathrm{n}_{0.17} \mathrm{~N} / \mathrm{AIN} / \mathrm{GaN}$ heterostructures measured at $1.8 \mathrm{~K}$. Filled squares correspond to the data given in Fig. 3. The straight line is the least-squares fit to the experimental data. The insert shows the fast Fourier spectrum of the oscillations $\left(N=2^{8}\right.$ and $\Delta T=4.9 \times 10^{-2} \mathrm{~T}^{-1}$ is the sampling interval). There is no evidence for population of higher subbands or for any contribution from higher harmonics.

$\left(E_{\mathrm{F}}-E_{1}\right)$ have been obtained from the oscillation period using Eq. (3) together with the in-plane effective mass $m^{*}$ of $2 \mathrm{D}$ electrons as obtained from the temperature dependence of $\mathrm{SdH}$ oscillations (see below). The results found for $E_{\mathrm{F}}-E_{1}$ are given in Table I.

The $2 \mathrm{D}$ carrier density in the $\mathrm{Al}_{0.83} \mathrm{In}_{0.17} \mathrm{~N} / \mathrm{AlN} /$ GaN sample determined from the $\mathrm{SdH}$ oscillations and the sheet carrier density $\left(N_{\mathrm{H}}\right)$ obtained from the low-field Hall-effect measurements at $1.8 \mathrm{~K}$ are also included in Table I. It can be seen that, within the experimental error owing to the $\mathrm{SdH}$ oscillations, the sheet carrier density determined is larger than the carrier density of $2 \mathrm{D}$ electrons. This indicates that parallel conduction due to carriers outside the $2 \mathrm{D}$ channel is effective for this sample at low temperatures.

The in-plane effective mass of $2 \mathrm{D}$ electrons in the $\mathrm{Al}_{0.83} \mathrm{In}_{0.17} \mathrm{~N} / \mathrm{AlN} / \mathrm{GaN}$ heterostructure can be determined from the temperature dependence of the $\mathrm{SdH}$ amplitude at constant magnetic field using Eq. (4). A typical example for the variation of $\mathrm{SdH}$ oscillation amplitude with temperature is shown in Fig. 5. The relative amplitude $A\left(T, B_{n}\right) / A\left(T_{0}, B_{n}\right)$ decreases with increasing temperature in accordance with the usual thermal damping factor [see Eq. (2)]. The in-plane effective mass of $2 \mathrm{D}$ electrons determined by fitting the experimental data for the temperature dependence of $A\left(T, B_{n}\right) / A\left(T_{0}, B_{n}\right)$ to Eq. (4) is also included in Table I. Similar analysis for all the oscillation peaks observed in the magnetic field range from $7 \mathrm{~T}$ to $11 \mathrm{~T}$ has established that the in-plane effective mass of the $2 \mathrm{D}$ electrons is essentially independent of the magnetic field.

Experimentally evaluated electron effective mass in $\mathrm{AlGaN} / \mathrm{GaN}$ as a function of the two-dimensional electron gas density formed at the interface of an $\mathrm{AlGaN} / \mathrm{GaN}$ heterostructure with a different alloy 

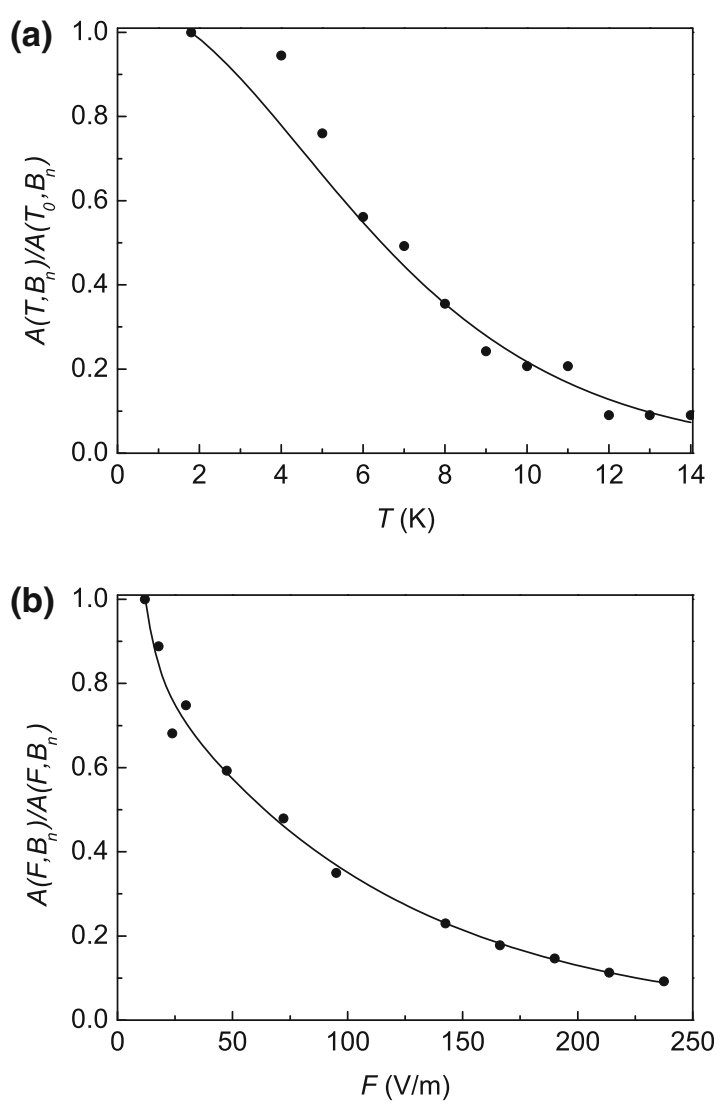

Fig. 5. (a) Temperature and (b) electric field dependencies of the normalized amplitude of the oscillation peak at $B_{n}$ measured in an $\mathrm{Al}_{0.83} \mathrm{In}_{0.17} \mathrm{~N} / \mathrm{AIN} / \mathrm{GaN}$ heterostructure. The data points represented by the filled circles correspond to the $\mathrm{SdH}$ oscillations arising from the electrons in the first subband. The solid curve in (a) is the best fit of Eq. (4) to the experimental data. The solid curve in (b) is intended as a guide for the eye.

composition was summarized by Kurakin et al. ${ }^{46}$ They found the electron effective mass in AlGaN/ $\mathrm{GaN}$ to be independent of the electron concentration. This result for the effective mass of $2 \mathrm{D}$ electrons was in good agreement with the bulk effective mass in GaN, which was reported ${ }^{46,47}$ to be $0.2 \pm 0.02 m_{0}$ (where $m_{0}$ is the free electron mass). The effective mass of $2 \mathrm{D}$ electrons in the $\mathrm{Al}_{0.83} \mathrm{In}_{0.17} \mathrm{~N} / \mathrm{AlN} / \mathrm{GaN}$ heterostructure is in good agreement with the bulk effective mass in GaN. ${ }^{46,47}$ This indicates that both the nonparabolicity of the conduction band of GaN and the wave function penetration into the AlN barrier/spacer layer have no significant effects on the effective mass of $2 \mathrm{D}$ electrons in our samples.

The SdH oscillations and classical Hall-effect measurements allow for determination of both the quantum and transport lifetimes of the electrons in the $\mathrm{Al}_{0.83} \mathrm{In}_{0.17} \mathrm{~N} / \mathrm{AlN} / \mathrm{GaN}$ heterostructure and hence to investigate the relative importance of various scattering mechanisms including ionized impurity scattering, alloy scattering, and interface roughness scattering. The quantum lifetime $\left(\tau_{\mathrm{q}}\right)$ can be determined from the magnetic field dependence

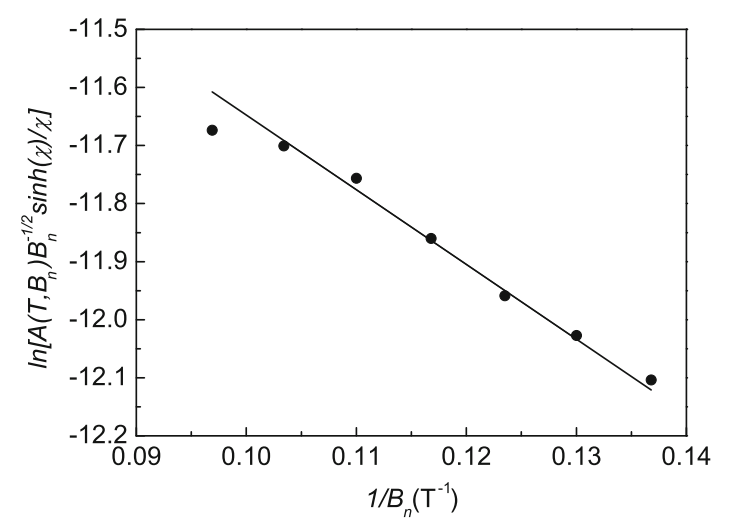

Fig. 6. Determination of the quantum lifetime in the $\mathrm{Al}_{0.83} \mathrm{In}_{0.17}$ $\mathrm{N} / \mathrm{AIN} / \mathrm{GaN}$ heterostructure sample. The data points are represented by solid squares, and the straight line is the least-squares fit of Eq. (5) to the experimental data.

of the amplitude of the $\mathrm{SdH}$ oscillations using Eq. (5) together with the measured values of $m^{*}$ (Table I). Figure 6 shows typical examples of the Dingle plots for the samples investigated. There is good agreement between the experimental data and the straight line described by Eq. (5). The quantum lifetime obtained from the slope of the Dingle plot is also included in Table I. These values remain constant within $2 \%$ in the whole temperature and magnetic field ranges of the measurements. The quantum lifetime $\left(\tau_{\mathrm{q}}\right)$ and quantum mobility $\left(\mu_{\mathrm{q}}\right)$ are also tabulated together with the transport lifetime $\left(\tau_{\mathrm{tr}}\right)$ and Hall mobility $\left(\mu_{\mathrm{H}}\right)$ determined using the results of zero-field resistivity and low-field Halleffect measurements in Table I.

The transport mobilities $\left(\mu_{\mathrm{t}}\right)$ of the $2 \mathrm{D}$ electrons in the quantum well have been calculated using the values (Table I) determined experimentally for the sheet carrier density $\left(N_{\mathrm{H}}\right), 2 \mathrm{D}$ carrier density $\left(N_{2 \mathrm{D}}\right)$, and Hall mobility $\left(\mu_{\mathrm{H}}\right)$ by following the analysis for parallel conduction by Kane et al. ${ }^{48}$ The expressions for the effective Hall mobility and carrier density due to the two conducting channels (quantum well and bulk carriers outside the $2 \mathrm{D}$ channel) may be written as

$$
\begin{gathered}
N_{\mathrm{H}}=\frac{\left(N_{2 \mathrm{D}} \mu_{\mathrm{t}}+N_{\mathrm{B}} \mu_{\mathrm{B}}\right)^{2}}{N_{2 \mathrm{D}} \mu_{\mathrm{t}}^{2}+N_{\mathrm{B}} \mu_{\mathrm{B}}^{2}}, \\
\mu_{\mathrm{H}}=\frac{N_{2 \mathrm{D}} \mu_{\mathrm{t}}^{2}+N_{\mathrm{B}} \mu_{\mathrm{B}}^{2}}{N_{2 \mathrm{D}} \mu_{\mathrm{t}}+N_{\mathrm{B}} \mu_{\mathrm{B}}},
\end{gathered}
$$

where $N_{\mathrm{B}}$ and $\mu_{\mathrm{B}}$ are the electron density and the mobility of the bulk carriers outside the $2 \mathrm{D}$ channel. Here, $N_{\mathrm{B}}$ is calculated from the difference between $N_{\mathrm{H}}$ and $N_{2 \mathrm{D}}$. The transport mobility (or transport lifetime) of $2 \mathrm{D}$ electrons in the $\mathrm{Al}_{0.83} \mathrm{In}_{0.17} \mathrm{~N} / \mathrm{AlN} /$ $\mathrm{GaN}$ heterostructure sample has been found to be essentially independent of both the lattice temperature in the range from $1.8 \mathrm{~K}$ to $14 \mathrm{~K}$ and the applied electric field in the range from $11.87 \mathrm{~V} \mathrm{~m}^{-1}$ to $230 \mathrm{~V} \mathrm{~m}^{-1}$. 


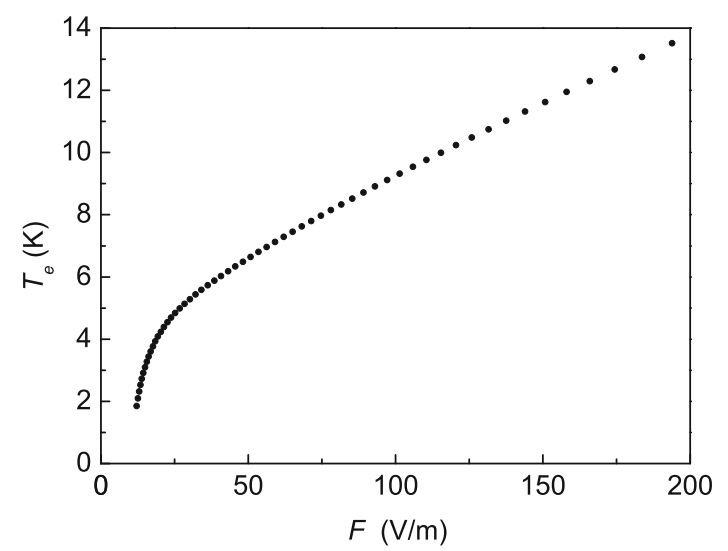

Fig. 7. Electron temperature $\left(T_{\mathrm{e}}\right)$ versus applied electric field $(F)$ for $\mathrm{Al}_{0.83} \mathrm{In}_{0.17} \mathrm{~N} / \mathrm{AIN} / \mathrm{GaN}$ heterostructures.

The ratio of the quantum to transport lifetime, $\tau_{\text {tr }} \tau_{\mathrm{q}}$, in our samples is larger than unity (Table I). Theoretical calculations relating the $2 \mathrm{D}$ single-particle scattering time (quantum lifetime) to the momentum relaxation time (transport lifetime) predict a $\tau_{\text {tr }} / \tau_{\mathrm{q}}$ ratio equal to or less than unity for wide-angle scattering and greater than unity for small-angle scattering in the extreme quantum limit for single subband occupancy. ${ }^{25}$ This implies that, in our sample, electron scattering with smallangle scattering, such as remote ionized impurity scattering and ionized surface states, is on average forward displaced in momentum space. A similar result is also attributed to $\mathrm{AlGaN} / \mathrm{GaN}$ heterostructures. ${ }^{19}$

Assuming that the change in the $\mathrm{SdH}$ amplitude with applied electric field can be described in terms of electric field-induced electron heating, the temperature $T$ in Eqs. (1-5) can be replaced by the electron temperature $T_{\mathrm{e}}{ }^{3,8,9,25}$ Therefore, $T_{\mathrm{e}}$ can be determined by comparing the relative amplitudes of the $\mathrm{SdH}$ oscillations measured as functions of the lattice temperature $\left(T=T_{\mathrm{L}}\right)$ and the applied electric field $(F)$ using ${ }^{3,8,9}$

$$
\left[\frac{A\left(T_{\mathrm{L}}, B_{n}\right)}{A\left(T_{\mathrm{L} 0}, B_{n}\right)}\right]_{F=F_{0}}=\left[\frac{A\left(F, B_{n}\right)}{A\left(F_{0}, B_{n}\right)}\right]_{T_{\mathrm{L}}=T_{\mathrm{L} 0}} .
$$

Here, $A\left(F, B_{n}\right)$ and $A\left(F_{0}, B_{n}\right)$ are the amplitudes of the oscillation peaks observed at a magnetic field $B_{n}$ and at electric fields $F$ and $F_{0}$, respectively. In order to obtain the electron temperature from the lattice temperature and electric field dependencies of the amplitude of the SdH oscillations, the quantum lifetime has to be independent of both the lattice temperature and the applied electric field. Figure $5 \mathrm{~b}$ shows the amplitudes of the $\mathrm{SdH}$ oscillations, normalized as described by Eq. (18), as functions of $F$ for the $\mathrm{Al}_{0.83} \mathrm{In}_{0.17} \mathrm{~N} / \mathrm{AlN} / \mathrm{GaN}$ heterostructure sample. In Fig. 5, only the relative amplitudes at a given magnetic field $B_{n}$ are shown for clarity. A similar analysis conducted for all the $\mathrm{SdH}$ peaks that were observed in the magnetic field range from $7 \mathrm{~T}$ to

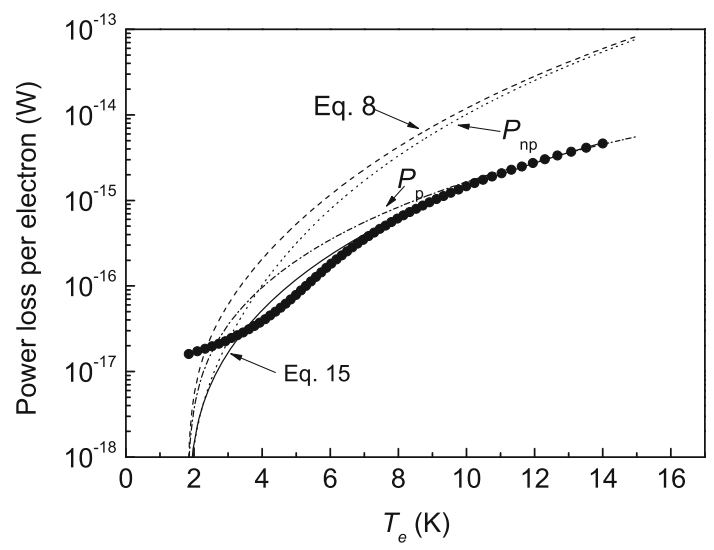

Fig. 8. Electron temperature dependence of power loss per electron determined from $\mathrm{SdH}$ measurements. Solid circles correspond to experimental data. Dashed, dotted, dash-dotted, and solid curves correspond to the power loss calculated using Eq. (8), nonpolar component of Eq. (8) $\left(P_{\mathrm{np}}\right)$, polar component of Eq. (8) $\left(P_{\mathrm{p}}\right)$, and Eq. (15), respectively.

$11 \mathrm{~T}$ has established that the relative amplitudes of $\mathrm{SdH}$ oscillations (and hence the electron temperatures) in our samples are essentially independent of magnetic field. This indicates that the magnetic field used in our experiments does not significantly alter the energy relaxation processes of hot electrons.

Electron temperatures $\left(T_{\mathrm{e}}\right)$ for the $\mathrm{Al}_{0.83} \mathrm{In}_{0.17}$ N/AlN/GaN heterostructure sample as obtained by directly comparing the curves similar to those in Fig. 5a, b are plotted as a function of the applied electric field in Fig. 7. The $\mathrm{SdH}$ oscillations measured for the $\mathrm{Al}_{0.83} \mathrm{In}_{0.17} \mathrm{~N} / \mathrm{AlN} / \mathrm{GaN}$ heterostructure sample decrease rapidly with increasing applied electric field and become vanishingly small for $F>230 \mathrm{~V} \mathrm{~m}^{-1}$ (Figs. 3b, 5b). The electron temperature determined for this sample rises quickly with increasing $F$.

In the steady state, the power loss from hot electrons by the emission of acoustic phonons is equal to the power supplied by the applied electric field, which can be calculated using the energy balance equation $^{8,9}$

$$
P=e \mu_{\mathrm{t}} F^{2},
$$

where $P, \mu_{\mathrm{t}}$, and $F$ are the energy loss (or energy supply) rate per electron/hole, transport mobility, and applied electric field, respectively. In the calculations of power loss, we used the calculated transport mobilities as given in Table I. The power loss versus electron temperature is plotted in Fig. 8 .

Comparing our results determined from $\mathrm{SdH}$ measurements with previous reports on energy relaxation of hot electrons in GaN/AlGaN heterojunctions, we find that the magnitude of the power loss determined in this study varies significantly from the power loss given in literature. ${ }^{17-20}$ The observed variations in power loss may be associated with the differences in the mobility of the samples, 
Table II. Material parameters of the $\mathrm{Al}_{0.83} \mathrm{In}_{0.17}$ N/AIN/GaN heterostructure used in the calculation (Refs. 20,50-52)

\begin{tabular}{lc}
\hline Parameter & Value \\
\cline { 1 - 2 }$\Xi(\mathrm{eV})$ & -7.7 \\
$\varepsilon_{\mathrm{S}}\left(\varepsilon_{0}\right)$ & 10 \\
$C_{11}(\mathrm{GPa})$ & 296 \\
$C_{12}(\mathrm{GPa})$ & 141 \\
$C_{44}(\mathrm{GPa})$ & 94 \\
$e_{14}\left(\mathrm{C} \mathrm{m}^{-2}\right)$ & 0.375 \\
$\left.\rho(\mathrm{kg} \mathrm{m})^{-3}\right)$ & 6150 \\
$V_{\mathrm{S}}(\mathrm{m} / \mathrm{s})$ & 6560 \\
$V_{\mathrm{b}}(\mathrm{eV})$ & 1.923 \\
$N_{\mathrm{D}}\left(\mathrm{cm}^{-3}\right)$ & $10^{18}$ \\
\hline
\end{tabular}

due to its primary role in the calculation of the power loss [see Eq. (21)]. If experimentally determined electron temperature-dependent power loss data are normalized to the mobility, it can be shown that the power loss determined from $\mathrm{SdH}$ measurements in literature ${ }^{17-20}$ and our results (Fig. 8) match each other rather well.

We found the exponent 3.55 (Table I) by fitting Eq. (15) to the experimental data determined from $\mathrm{SdH}$ measurements (Fig. 8). In all cases, a constant value for the exponent $\gamma$ is obtained over the whole temperature range. This indicates that the experiments were carried out in the low-temperature regime and that the energy relaxation is due to acoustic phonon emission via mixed unscreened piezoelectric and deformation potential interactions. ${ }^{2,49}$

We, therefore, fitted the experimental $P\left(T_{\mathrm{e}}\right)$ data, obtained from the measurements at $T_{\mathrm{L} 0} \approx 1.8 \mathrm{~K}$, to the analytical expressions for power loss in the lowtemperature regime (Fig. 8). The power loss, as given by Eq. (8), was calculated using the values (Table I) determined experimentally for the effective mass, carrier density, and Fermi energy of 2D electrons in the $\mathrm{Al}_{0.83} \mathrm{In}_{0.17} \mathrm{~N} / \mathrm{AlN} / \mathrm{GaN}$ heterostructure sample; other parameters were taken from the literature (Table II). ${ }^{20,50-52}$

We attempted to fit the 2D theoretical power loss in the low-temperature regime (Eq. 8) to the experimental $P\left(T_{\mathrm{e}}\right)$ results determined from $\mathrm{SdH}$ measurements. However, the low-temperature regime model does not offer a satisfactory fit to the experimental data for the $\mathrm{Al}_{0.83} \mathrm{In}_{0.17} \mathrm{~N} / \mathrm{AlN} / \mathrm{GaN}$ heterostructure sample. It is also instructive to study the relative magnitude of the deformation potential (nonpolar acoustic) $P_{\mathrm{np}}$ and piezoelectric (polar acoustic) $P_{\mathrm{p}}$ components of the electron energy loss rates. In the low-temperature regime, the piezoelectric coupling dominates: $P_{\mathrm{np}} / P_{\mathrm{p}}>1$ for the $\mathrm{Al}_{0.83} \mathrm{In}_{0.17} \mathrm{~N} / \mathrm{AlN} / \mathrm{GaN}$ heterostructure sample. These trends remain at all electron temperatures in the range from $1.8 \mathrm{~K}$ to $14 \mathrm{~K}$. The polar and nonpolar components of the power loss in the low-temperature regime are also plotted as a function of electron temperature in Fig. 8. It is evident from Fig. 8 that $P_{\mathrm{p}}$ is in agreement with the experimental power loss data determined above $8 \mathrm{~K}$ for the $\mathrm{Al}_{0.83} \mathrm{In}_{0.17} \mathrm{~N} / \mathrm{AlN} / \mathrm{GaN}$ heterostructure sample. This result is also in accord with the outcome of fitting Eq. (15) and other researchers' results in AlGaN/GaN heterojunctions. ${ }^{17-20}$ To our knowledge, there is no study to date concerning acoustic phonon-assisted energy relaxation of hot electrons in AlInN/AlN/GaN or AlInN/GaN heterostructure samples. Therefore, we have no possibility to compare our experimental results with experimental results from literature.

The dominant process for relaxing the hot electron energy is via the interaction with acoustic phonons below about $100 \mathrm{~K}$ and polar optical phonons at $300 \mathrm{~K}$ in GaN-based heterostructures. ${ }^{5,54}$ The acoustic phonon scattering includes deformation potential scattering and piezoelectric scattering. In view of our experimental observations, we conclude that, in the low-temperature regime, the piezoelectric scattering rates in the $2 \mathrm{D}$ case are somewhat overestimated for the $\mathrm{Al}_{0.83} \mathrm{In}_{0.17} \mathrm{~N} / \mathrm{AlN} /$ $\mathrm{GaN}$ heterostructure and, hence, the theoretical calculations of the 2D polar interactions need to be reconsidered. From the theoretical calculation, it was shown that in the energy relaxation rates for acoustic phonons the lattice temperature determines the number of excited phonons and the electron temperature affects the screening., ${ }^{2,53}$ If screening were to be included in the $2 \mathrm{D}$ theoretical calculations for the GaN-based structure, the nonpolar component of the interaction would be reduced significantly for

$$
\frac{k}{\sqrt{2 m^{*} \omega_{\mathrm{LO}} / \hbar}}<1,
$$

where $k$ is the electron wavevector and $\omega_{\mathrm{LO}}$ is the optical phonon frequency, ${ }^{53}$ whereas, if screening were to be included in the $2 \mathrm{D}$ theoretical calculations for the GaAs-based structure, the polar component of the interaction would be reduced significantly. ${ }^{2,5,7}$ Therefore, in order to compare our experimental results with the theoretical results and the calculation using Eq. 23, we used our experimental data to determine the optical phonon energy.

The techniques that are often used to find the optical phonon (LO) energy are Raman or infrared measurements, temperature-dependent Hall mobility measurements, and hot electron power loss measurements. While the first technique gives the LO energy directly from the spectra, the two latter techniques yield this value via use of appropriate energy and momentum relaxation expressions.

In the temperature range above approximately $90 \mathrm{~K}$, where the electron mobility is expected to be limited primarily by polar optical phonon scattering, the temperature dependence of the differential 


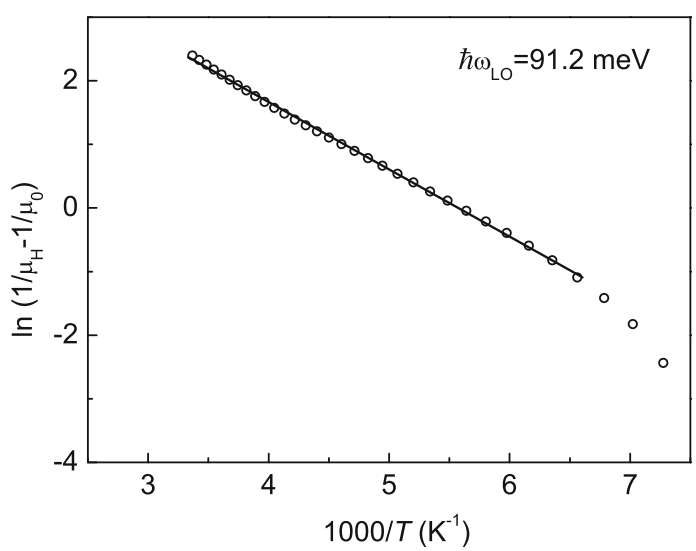

Fig. 9. The natural logarithm of the differential inverse mobility as a function of inverse temperature for an $\mathrm{Al}_{0.83} \mathrm{In}_{0.17} \mathrm{~N} / \mathrm{AIN} / \mathrm{GaN}$ heterostructure. For symbols, refer to Fig. 1. The straight line is a least-squares fit to the experimental data.

inverse mobility $\left(1 / \mu_{\mathrm{H}}-1 / \mu_{0}\right)$ can be approximated by $^{55-57}$

$$
\frac{1}{\mu_{\mathrm{LO}}}=\frac{1}{\mu_{\mathrm{H}}}-\frac{1}{\mu_{0}}=\frac{2 m^{*} \alpha \omega_{\mathrm{LO}}}{e} \exp \left(-\frac{\hbar \omega_{\mathrm{LO}}}{k_{\mathrm{B}} T}\right)
$$

where $\mu_{0}$ is the low-temperature Hall mobility, which is independent of temperature, $\mu_{\mathrm{H}}$ is the temperature-dependent Hall mobility measured at temperatures above approximately $90 \mathrm{~K}, \alpha$ is the dimensionless polar constant, and $\omega_{\mathrm{LO}}$ is the angular frequency of the optical phonon mode. Therefore, the LO phonon energy can be determined from a plot of the natural logarithm of $\left(1 / \mu_{\mathrm{H}}-1 / \mu_{0}\right)$ versus $1 / T$. Figure 9 presents such a plot of the natural logarithm of $\left(1 / \mu_{\mathrm{H}}-1 / \mu_{0}\right)$ versus $1 / T$. The LO phonon energy determined from the slope of the straight line, which is the best fit to the experimental data above approximately $170 \mathrm{~K}$, is $\hbar \omega_{\text {LO }}=91.2 \mathrm{meV}$.

Figure 10 shows the room-temperature Raman spectrum for the $\mathrm{Al}_{0.83} \operatorname{In}_{0.17} \mathrm{~N} / \mathrm{AlN} / \mathrm{GaN}$ heterostructure sample recorded in the grown-axis backscattering configuration $(z(x x) \bar{z})$. In our sample, GaN crystallizes in a wurtzite structure whose $z$-axis is perpendicular to the sapphire substrate plane. The space group is $C_{6 v}^{4}$, and the $\mathrm{A}_{1}(\mathrm{LO})$ and $\mathrm{E}_{2}$ modes are allowed in this configuration. ${ }^{58}$ There is a sharp and strong peak at $575 \mathrm{~cm}^{-1}$, known as the nonpolar high-frequency $\mathrm{E}_{2}$ mode, which implies a strong correlation between $\mathrm{Ga}$ and $\mathrm{N}$ atoms on the $c$-plane.$^{58-60}$ The polar vibrations $\mathrm{A}_{1}(\mathrm{LO})$ observed at $738.5 \mathrm{~cm}^{-1}$ also correspond to a correlation between $\mathrm{Ga}$ and $\mathrm{N}$ atoms. Since the light penetration depth of $785 \mathrm{~nm}$ is longer than the thickness of the coated wafer on the sapphire substrate, the sapphire origin $\mathrm{A}_{1 g}$ and $\mathrm{E}_{\mathrm{g}}$ modes were observed at approximately $644 \mathrm{~cm}^{-1}$ and $754 \mathrm{~cm}^{-1}$, respectively. The energy of $\mathrm{LO}$ phonons in GaN $\left(\hbar \omega_{\mathrm{LO}}=91.6 \mathrm{meV}\right)$ is determined using $\hbar \omega_{\mathrm{LO}}=\hbar c \bar{v}$,

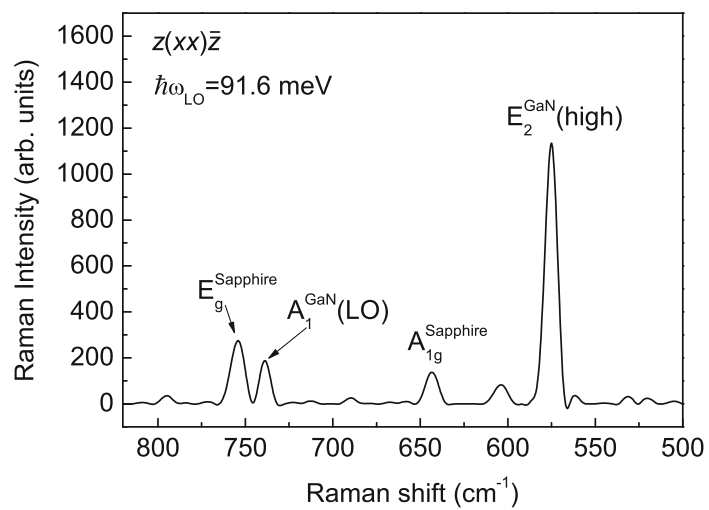

Fig. 10. Room-temperature Raman spectrum for the $\mathrm{Al}_{0.83} \mathrm{In}_{0.17}$ N/AIN/GaN heterostructure sample.

where $c$ is the speed of light and $\bar{v}$ is the wavenumber of the $\mathrm{A}_{1}(\mathrm{LO})$ mode. The value for $\hbar \omega_{\mathrm{LO}}$ determined by this method is in good agreement with that $\left(\hbar \omega_{\mathrm{LO}}=91.2 \mathrm{meV}\right)$ obtained from our present mobility measurements and that $\left(\hbar \omega_{\mathrm{LO}}=\right.$ $91.8 \mathrm{meV}$ ) reported in literature. ${ }^{61,62}$

We found that the ratio given in Eq. 23 is less than and equal to 1 using $k<k_{\mathrm{F}}$ and our experimentally evaluated optical phonon energy. Therefore, it can be stated that the energy loss rate per electron for the $\mathrm{Al}_{0.83} \mathrm{In}_{0.17} \mathrm{~N} / \mathrm{AlN} / \mathrm{GaN}$ heterostructure sample in the acoustic phonon regime is in agreement with the theoretical results. In addition, there is a small deviation between the experiment and theory at low electron temperature. This is probably because the ideal quantum-well approximation in the extreme quantum limit, which was used in the $2 \mathrm{D}$ power loss calculations, predicts an enhancement in the confined electron-acoustic phonon interaction, compared with the case in a real triangle quantum well with finite barriers in our $\mathrm{Al}_{0.83} \operatorname{In}_{0.17} \mathrm{~N} / \mathrm{AlN} / \mathrm{GaN}$ heterostructure. , $^{2,7,49}$ Furthermore, the existing $2 \mathrm{D}$ theories use the bulk phonon approximation, which requires consideration of the confinement and folding of the longitudinal and transverse acoustic modes.

The energy relaxation time $\left(\tau_{\mathrm{E}}\right)$ for intrasubband processes can be obtained from the power loss measurements using ${ }^{2}$

$$
P=\frac{<\hbar \omega>}{\tau_{\mathrm{E}}} \frac{\left(k_{\mathrm{B}} T_{\mathrm{e}}-k_{\mathrm{B}} T_{\mathrm{L}}\right)}{k_{\mathrm{B}} T_{\mathrm{e}}},
$$

where $<\hbar \omega>=2^{1 / 2} \hbar V_{\mathrm{S}} k_{\mathrm{F}}$ and $<\hbar \omega>$ is the acoustic phonon energy averaged over the Fermi surface. Figure 11 shows the energy relaxation time as a function of electron temperature for the $\mathrm{Al}_{0.83} \mathrm{In}_{0.17}$ N/AlN/GaN heterostructure sample studied. Such large values of $\tau_{\mathrm{E}}$ indicate that the energy loss mechanism in this temperature range is not very efficient and leads to rapid rise of the electron temperature when the input power is increased (Fig. 8). However, as can be seen in Fig. 11, the 


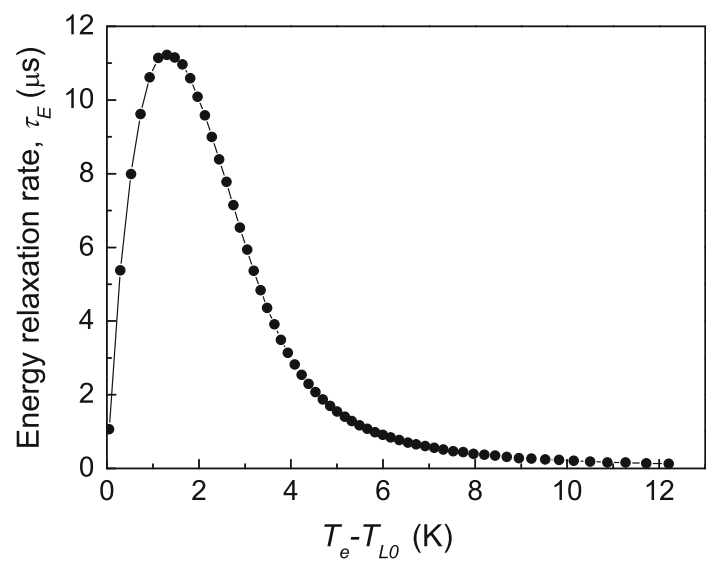

Fig. 11. Energy relaxation time $\left(t_{\mathrm{e}}\right)$ versus $T_{\mathrm{e}}-T_{\mathrm{LO}}$ for the $\mathrm{Al}_{0.83} \mathrm{In}_{0.17} \mathrm{~N} / \mathrm{AIN} / \mathrm{GaN}$ heterostructure. The solid curves through the experimental data points are intended as a guide for the eye.

energy relaxation due to acoustic phonons becomes faster at higher electron temperatures.

\section{CONCLUSIONS}

The carrier density $\left(N_{2 \mathrm{D}}\right)$, effective mass $\left(m^{*}\right)$, and quantum lifetime $\left(\tau_{\mathrm{q}}\right)$ for electrons in an $\mathrm{Al}_{0.83} \mathrm{In}_{0.17} \mathrm{~N} / \mathrm{AlN} / \mathrm{GaN}$ heterostructure have been determined from the Shubnikov-de Haas ( $\mathrm{SdH})$ oscillations. The two-dimensional (2D) carrier density and the Fermi energy with respect to the subband energy $\left(E_{\mathrm{F}}-E_{1}\right)$ have been obtained from the periods of the SdH oscillations. The $m^{*}$ and $\tau_{\mathrm{q}}$ of electrons have been extracted from the temperature and magnetic field dependencies of the $\mathrm{SdH}$ amplitude, respectively. The results obtained for the transport-to-quantum lifetime ratios of the respective subbands indicate that the scattering of electrons by remote ionized impurities is on average forward displaced in momentum space.

The energy loss rates, in the acoustic phonon regime, of $2 \mathrm{D}$ electrons in an $\mathrm{Al}_{0.83} \mathrm{In}_{0.17} \mathrm{~N} / \mathrm{AlN} / \mathrm{GaN}$ heterostructure have also been investigated using $\mathrm{SdH}$ effect measurements. The experimental results were compared with the predictions of current theoretical models for power loss in semiconductors. The energy relaxation of electrons is due to acoustic phonon emission via unscreened piezoelectric interaction. In the low-temperature regime, the piezoelectric component is significantly greater than the deformation potential component of the $2 \mathrm{D}$ power loss, for electron temperatures lower than $14 \mathrm{~K}$.

\section{ACKNOWLEDGEMENTS}

We are grateful to TUBITAK Ankara (Project No. 110T377) and Anadolu University (Project No. BAP1001F99) for their financial support.

\section{REFERENCES}

1. H. Morkoc, Handbook of Nitride Semiconductors and Devices, Vol. I-III. (Weinheim: Wiley-VCH, 2008).
2. B.K. Ridley, Rep. Prog. Phys. 54, 169 (1991).

3. N. Balkan, H. Celik, A.J. Vickers, and M. Cankurtaran, Phys. Rev. B 52, 17210 (1995).

4. N. Balkan, Hot Electrons in Semiconductors: Physics and Devices. (Oxford: Clarendon, 1998).

5. P.J. Price, J. Appl. Phys. 53, 6863 (1982).

6. S.D. Sarma, J.K. Jain, and R. Jalabert, Phys. Rev. B 37, 6290 (1989).

7. Y. Okuyama and N. Tokuda, Phys. Rev. B 40, 9744 (1989).

8. H. Kahlert and G. Bauer, Phys. Status Solidi B 46, 535 (1971).

9. G. Bauer and H. Kahlert, Phys. Rev. B 5, 566 (1972).

10. M.C. Arikan, A. Straw, and N. Balkan, J. Appl. Phys. 74, 6261 (1993).

11. S. Mazzucato, M.C. Arikan, N. Balkan, B.K. Ridley, N. Zakhleniuk, R.J. Shealy, and B. Schaff, Phys. B 314, 55 (2002).

12. N. Balkan, M.C. Arikan, S. Gokten, V. Tilak, and B. Schaff, J. Phys. Condens. Matter 14, 3457 (2002).

13. A. Ilgaz, S. Gokten, R. Tulek, A. Teke, S. Ozcelik, and E. Ozbay, Eur. Phys. J. Appl. Phys. 55, 30102 (2011).

14. A. Matulionis, J. Liberis, E. Sermuksnis, J. Xei, J.H. Leach, M. Wu, and H. Morkoc, Semicond. Sci. Technol. 23, 075048 (2008).

15. A. Matulionis, J. Phys. Condens. Matter 21, 174203 (2009).

16. K.T. Tsen, J.G. Kiang, D.K. Ferry, and H. Morkoc, Appl. Phys. Lett. 89, 112111 (2006).

17. K.J. Lee, J.J. Harris, A.J. Kent, T. Wang, S. Sakai, D.K. Maude, and J.C. Portal, Appl. Phys. Lett. 78, 2893 (2001).

18. N.M. Stanton, A.J. Kent, S.A. Cavill, A.V. Akimov, K.J. Lee, J.H. Harris, T. Wang, and S. Sakai, Phys. Status Solidi B 228, 607 (2001).

19. C.E. Martinez, N.M. Stanton, A.J. Kent, M.L. Williams, I. Harrison, H. Tang, J.B. Webb, and J.A. Bardwell, Semicond. Sci. Technol. 21, 1580 (2006).

20. H. Cheng, N. Biyikli, J. Xie, C. Kurdak, and H. Morkoc, J. Appl. Phys. 106, 103702 (2009).

21. J. Xie, X. Ni, M. Wu, J.H. Leach, U. Ozgur, and H. Morkoc, Appl. Phys. Lett. 91, 132116 (2007).

22. R. Butte, J.-F. Carlin, E. Feltin, M. Gonschorek, S. Nicolay, G. Christmann, D. Simeonov, A. Castiglia, J. Dorsaz, H.J. Buemann, S.G. Baldassarri, H. von Hogersthal, A.J.D. Grundy, M. Mosca, C. Pinquier, M.A. Py, F. Demangeot, J. Frandon, P.G. Lagoudakis, J.J. Baumberg, and N. Grandjean, J. Phys. D Appl. Phys. 40 (2007).

23. A. Teke, S. Gokden, R. Tulek, J.H. Leach, Q. Fan, J. Xie, U. Ozgur, H. Morkoc, S.B. Lisesivdin, and E. Ozbay, New J. Phys. 11, 063031 (2009).

24. J. Shah, Hot carriers in Semiconductors Physics and Applications. (USA: Academic, 1992).

25. E. Tiras, M. Cankurtaran, H. Celik, and N. Balkan, Phys. Rev. B 64, 085301 (2001).

26. E. Tiras, N. Balkan, S. Ardali, M. Gunes, F. Fontaine, and A. Arnoult, Philos. Mag. 91, 628 (2011).

27. J. Shah, A. Pinczuk, H.L. Stormer, A.C. Gossard, and W. Wiegmann, Appl. Phys. Lett. 44, 322 (1984).

28. V. Karpus, Fiz. Tekh. Poluprovodn. 22, 439 (1988) [Sov. Phys. Semicond. 22, 268 (1988)].

29. A.M. Kreshchuk, M.Y. Martisov, T.A. Polyanskaya, I.G. Savel'ev, I.I. Saidashev, A.Y. Shik, and Y.V. Shmartsev, Fiz. Tekh. Poluprovodn. 22, 604 (1988) [Sov. Phys. Semicond. 22, 377 (1988)].

30. A.M. Kreshchuk, M.Y. Martisov, T.A. Polyanskaya, I.G. Savel'ev, I.I. Saidashev, A.Y. Shik, and Y.V. Shmartsev, Solid State Commun. 65, 1189 (1988).

31. P. Hawker, A.J. Kent, O.H. Hughes, and L.J. Challis, Semicond. Sci. Technol. 7, B29 (1992).

32. B.N. Murdin, W. Heiss, C.J.G.M. Langerak, S.-C. Lee, I. Galbraith, G. Strasser, E. Gornik, M. Helm, and C.R. Pidgeon, Phys. Rev. B 55, 5171 (1997).

33. T. Ando, J. Phys. Soc. Jpn. 37, 1233 (1974).

34. T. Ando, A.B. Fowler, and F. Stern, Rev. Mod. Phys. 54, 437 (1982).

35. E. Tiras, M. Cankurtaran, H. Celik, A. Boland-Thoms, and N. Balkan, Superlattices Microstruct. 29, 147 (2001). 
36. P.K. Milsom and P.N. Butcher, Semicond. Sci. Technol. 1, 58 (1986).

37. M.P. Vaughan and B.K. Ridley, Phys. Rev. B 72, 075211 (2005).

38. H. Celik, M. Cankurtaran, N. Balkan, and A. Bayrakli, Semicond. Sci. Technol. 17, 18 (2002).

39. G. Weimann, Festkorperprobleme Adv. Solid State Phys. 26, 231 (1986)

40. S. Hiyamizu, J. Saito, K. Nanbu, and T. Ishikawa, Jpn. J. Appl. Phys. 22, L609 (1983).

41. E.E. Mendez, P.J. Price, and M. Heiblum, Appl. Phys. Lett. 45, 294 (1984).

42. L. Ardaravicius, M. Ramonas, J. Liberis, O. Kiprijanovic, A. Matulionis, J. Xie, M. Wu, J.H. Leach, H. Morkoc, J. Appl. Phys. 106, 073708 (2009).

43. R.A. Stradling and R.A. Wood, J. Phys. C Solid State Phys. 3, L94 (1970).

44. H. Celik, M. Cankurtaran, A. Bayrakli, E. Tiras, and N. Balkan, Semicond. Sci. Technol. 12, 389 (1997).

45. M. Cankurtaran, H. Celik, E. Tiras, A. Bayrakli, and N. Balkan, Phys. Status Solidi B 207, 139 (1998).

46. A.M. Kurakin, S.A. Vitusevich, S.V. Danylyuk, H. Hardtdegen, N. Klein, Z. Bougrioua, A.V. Naumov, and A.E. Belyaev, J. Appl. Phys. 105, 073703 (2009).

47. I. Vurgaftman, J.R. Meyer, and L.R. Ram-Mohan, J. Appl. Phys. 89, 5815 (2001)

48. M.J. Kane, N. Apsley, D.A. Anderson, L.L. Taylor, and T. Kerr, J. Phys. C Solid State Phys. 18, 5629 (1985).
49. M. Cankurtaran, H. Celik, and N. Balkan, Phys. Status Solidi B 229, 1191 (2002).

50. W.J. Fan and S.F. Yoon, J. Appl. Phys. 90, 843 (2001).

51. S. Adachi, Properties of Semiconductor Alloys: Group IV, III-V and II-VI Semiconductors, 1st edn. (UK: Wiley, 2009).

52. A.D. Bykhovski, V.V. Kaminski, M.S. Shur, Q.C. Chen, and M.A. Khan, Appl. Phys. Lett. 68, 818 (1996).

53. P. Tripathi and B.K. Ridley, Phys. Rev. B 66, 195301 (2002).

54. C. Bulutay, B.K. Ridley, and N.A. Zakhleniuk, Phys. Rev. B 68, 115205 (2003)

55. K. Seeger, Semiconductor Physics-An Introduction, 6th ed. (New York: Springer-Verlag, 1997).

56. S. Altinoz, E. Tiras, A. Bayrakli, H. Celik, M. Cankurtaran, and N. Balkan, Phys. Status Solidi A 182, 717 (2000).

57. E. Tiras, M. Gunes, N. Balkan, and W.J. Schaff, Phys. Status Solidi B 247, 189 (2010).

58. T. Azuhata, T. Sota, K. Suzuki, and S. Nakamura, J. Phys. Condens. Matter 7, L129 (1995).

59. T. Kozawa, T. Kachi, H. Kano, Y. Taga, and M. Hashimoto, J. Appl. Phys. 75, 1098 (1994).

60. M. Ramsteiner, O. Brandt, and K.H. Ploog, Phys. Rev. B 58, 1118 (1998).

61. V.Yu. Davydov, Yu.E. Kitayev, I.N. Goncharuk, A.N. Smirnov, J. Graul, O. Semchinova, D. Uffmann, M.B. Smirnov, A.P. Mirgorodsky, and R.A. Evarestov, Phys. Rev. B 58, 12899 (1998).

62. M. Kuball, Surf. Interface Anal. 31, 987 (2001). 